\title{
Proposta de uma nova metodologia para calibração de rugosidades em redes com diferentes materiais
}

\section{Proposal of a new methodology for roughness calibration in networks with different materials}

Data de entrada: $19 / 08 / 2019$

Data de aprovação: 05/11/2019

David Lopes de Sousa ${ }^{1 *}$ | Alessandro de Araújo Bezerra² | Marco Aurélio Holanda de Castro'

DOI: https://doi.org/10.36659/dae.2021.002

ORCID ID

Sousa DL (D) https://orcid.org/0000-0001-8041-9511
Bezerra AA (D) https://orcid.org/0000-0002-9243-0731

Castro MAH (D) https://orcid.org/0000-0001-5134-7213

\section{Resumo}

A calibração de redes de distribuição de água é uma importante ferramenta para a obtenção de modelos computacionais que representem melhor a rede instalada. Neste trabalho foi desenvolvida uma nova rotina, que adapta o Método do Gradiente Hidráulico Alternativo (MIGHA), utilizado na calibração do fator de atrito e no cálculo da rugosidade absoluta, tornando mais uniformes os resultados obtidos para esse parâmetro nas tubulações que possuem o mesmo material. Além disso, foram testadas diferentes funções objetivo com o intuito de descobrir qual é a mais indicada para o método. Os resultados obtidos sugerem que a nova rotina de uniformização melhora consideravelmente as calibrações, retornando excelentes resultados, mesmo utilizando apenas $25 \%$ dos nós com pressões conhecidas. As diferentes funções objetivo testadas não influenciaram significativamente nos resultados.

Palavras-chave: Calibração. Rugosidade absoluta. Rotina de uniformização. Funções objetivo.

\section{Abstract}

Calibration of water distribution networks is an important tool for obtaining computational models that better represent the installed network. This work developed a new routine that adapts the Alternative Hydraulic Gradient Method (MIGHA), used in the friction factor calibration and absolute roughness calculation, making the results obtained for this parameter more uniform in the pipes that have the same material. In addition, different objective functions were tested in order to find out which one is the most suitable for the method. The results suggest that the new standardization routine considerably improves calibrations, returning excellent results, even using only $25 \%$ of nodes with known pressures. The different objective functions tested did not significantly influence the results.

Keywords: Calibration. Absolute roughness. Standardization routine. Objective functions.

\footnotetext{
${ }^{1}$ Universidade Federal do Ceará - Fortaleza - Ceará - Brasil.

2 Universidade Federal do Piauí - Teresina - Piauí - Brasil.

"Autor correspondente: david.lopes2ahotmail.com.
} 


\section{INTRODUÇÃO}

Nos centros urbanos, as redes de distribuição de água são essenciais para a manutenção do estilo de vida e da saúde da população. A garantia desse recurso em quantidade, qualidade e pressão é fundamental para estabelecer um padrão de vida aceitável e condizente com as necessidades atuais. Para tanto, as companhias de água necessitam cada vez mais de modelos computacionais que representem bem a rede instalada e que facilitem o seu acompanhamento. Além disso, modelos mais próximos da realidade facilitam a detecção de falhas e na criação de projetos de ampliação.

Para trabalhar com um modelo computacional coerente, é necessário conhecer alguns parâmetros da rede, tais como a rugosidade das tubulações, diâmetros, demandas, entre outros. No entanto, a vida útil desse tipo de projeto costuma ser longa, e é natural que com o passar do tempo os valores desses parâmetros se alterem. Segundo Vassiljev, Koor e Koppel (2015), a rugosidade e o diâmetro das tubulações sofrem alterações devido a processos de corrosão e acúmulos de sedimentos. Dito isso, surge a necessidade da utilização de métodos de calibração capazes de atualizar os valores desses parâmetros, utilizando-se comumente de dados de pressão ou vazão da rede instalada medidos em campo. Vasconcelos, Costa e Araújo (2015) definem a calibração em sistemas de distribuição de água como sendo um processo de identificação de parâmetros físicos e operacionais, passíveis de alteração com o tempo, que possibilita um mapeamento verdadeiro da rede.

Para Cheng e He (2011) existem três tipos de calibração aplicáveis a redes de distribuição de água: modelos de tentativa-e-erro; modelos de simulação ou métodos explícitos; modelos de otimização ou métodos implícitos. O terceiro vem sendo comumente utilizado em trabalhos recentes de calibração: Bezerra, Castro e Araújo (2017); Santos e Silva (2013), Cheng e He(2011). O método implícito consiste na minimização de uma função objetivo que torna os dados da rede calibrada mais próximos dos dados observados.

A técnica de calibração de rugosidades em redes de abastecimento de água utilizada neste trabaIho é o Método Iterativo do Gradiente Hidráulico Alternativo (MIGHA), um método implícito desenvolvido incialmente por Guo e Zhang (1994) para a calibração da transmissividade hidráulica em aquíferos subterrâneos. Esse método foi posteriormente adaptado por Schuster e Araújo (2004) e mais tarde por diversos autores para o seu uso em sistemas de distribuição de água. Entre eles, destacaram-se Rocha, Castro e Araújo (2009), Rocha (2013), Pereira e Castro (2013) e Bezerra, Castro e Araújo (2017).

O MIGHA, até então, não possui uma rotina que uniformiza as rugosidades de tubulações que são do mesmo material e da mesma idade. Portanto, a utilização desse método pode retornar valores de rugosidade muito diferentes para trechos que supostamente deveriam possuir valores próximos desse parâmetro.

Este trabalho tem como objetivo desenvolver uma adaptação ao MIGHA que uniformiza os resultados das rugosidades absolutas calibradas em trechos que possuem o mesmo material, bem como testar diferentes funções objetivo e verificar qual a mais indicada nas aplicações deste método.

\subsection{O Método Iterativo do Gradiente Hidráulico Alternativo (MIGHA)}

Em seu trabalho, Bezerra, Castro e Araújo (2017) propuseram a utilização do MIGHA na calibração do fator de atrito e posterior cálculo das rugosidades. O método utiliza como função objetivo a ser minimizada a Eq. 1. 
$f_{o b j}=\sum_{n T}\left(\nabla H_{O}-\nabla H_{C}\right)^{2}$

Em que $\nabla H_{\mathrm{o}}$ é o gradiente hidráulico (perda de carga unitária) do trecho na rede com dados observados, $\nabla \mathrm{H}_{\mathrm{C}}$ corresponde ao gradiente hidráulico da rede sem os dados observados e nT corresponde ao número total de trechos.

Para o cálculo dos gradientes hidráulicos em todos os trechos, o método faz uso de duas redes de distribuição, as quais são denominadas de Rede Calculada e Rede Observada. A Rede Calculada é a que possui suas rugosidades estimadas, as quais se deseja calibrar. Esses parâmetros são atualizados a cada iteração, aproximando seus dados de pressão e vazão para os medidos em campo. A Rede Observada possui seus parâmetros estimados iguais à Rede Calculada; no entanto, alguns de seus nós têm suas pressões fixadas de acordo com os dados medidos. Para utilizar o método com redes fictícias, faz-se o uso do conceito de Rede Gabarito, a qual possui todos os seus parâmetros corretos e de onde se retiram os dados de pressão para calibrar a Rede Calculada.

Bezerra, Castro e Araújo (2017), observando a proporcionalidade e a relação direta do gradiente hidráulico com o fator de atrito na fórmula de Darcy-Weisbach, propuseram a Eq. 2 para a calibração do fator de atrito.

$$
f_{j}^{i+1}=f_{j}^{i}\left(\frac{\left|\nabla H_{C_{j}}^{i}\right|}{\left|\nabla H_{O_{j}}^{i}\right|}\right)^{-1}
$$

Em que $f$ é o fator de atrito, o índice i representa a iteração, e o índice j, o trecho.

O software desenvolvido pelos autores para calibrar as redes utiliza a biblioteca do EPANET2 para realizar as simulações hidráulicas. Essa biblioteca utiliza a fórmula de Swamie-Jain para o cálculo do fator de atrito, descrita na Eq. 3.

$$
f=\frac{0,25}{\left[\log \left(\frac{\varepsilon}{3,7 D}+\frac{5,74}{R e y^{0,9}}\right)\right]^{2}}
$$

Em que $\varepsilon$ é a rugosidade absoluta, $D$ é o diâmetro do trecho e Rey é o número de Reynolds.

Como o objetivo final é calibrar a rugosidade absoluta, esta foi isolada na Eq. 3, resultando nas Eq. 4 e 5:

$$
\begin{aligned}
& \varepsilon=3.7 D \times 10^{0.5 / \sqrt{f}}-\frac{21.238 \times D}{\operatorname{Rey}^{0.9}} \\
& \varepsilon=\frac{3.7 D \times\left(\operatorname{Rey}^{0,9}-5.74 \times 10^{0,5 / \sqrt{f}}\right)}{\operatorname{Re} y^{0,9} \times 10^{0.5 / \sqrt{f}}}
\end{aligned}
$$

As rugosidades absolutas calculadas pela Eq. 4 possuem ordens de grandeza muito elevadas, portanto essa equação foi descartada pelos autores. Deste modo, este método, que será adotado neste trabalho, segue a seguinte rotina: simulação da rede inicial; cálculo da função objetivo com o uso da Eq. 1; cálculo dos novos fatores de atrito com a Eq. 2 e cálculo das novas rugosidades para a próxima iteração com a Eq. 5. Caso a rugosidade calculada para algum trecho seja negativa ou maior do que $12 \mathrm{~mm}$, esta é descartada e será mantida a mesma rugosidade para a próxima iteração. Esse processo se repete até que um valor objetivo tenha sido alcançado ou um número máximo de iterações tenha sido atingido.

Ressalta-se que esse método é utilizado aqui para calibrar as rugosidades, admitindo-se que os outros parâmetros (consumos nodais, diâmetros, etc) sejam conhecidos. 


\section{METODOLOGIA}

\subsection{Nova Rotina de Uniformização}

Analisando a metodologia proposta por Bezerra, Castro e Araújo (2017), observou-se que não existe um critério que uniformize as rugosidades calibradas em trechos que possuem o mesmo material. Deste modo, é comum obter como resultado final dessa calibração um ou mais tubos onde esse parâmetro se encontra com ordem de grandeza diferente dos demais trechos com material de mesmo tipo.

Neste trabalho, é proposta uma nova rotina de cálculo que adapta a metodologia de Bezerra, Castro e Araújo (2017), uniformizando as rugosidades calibradas dos trechos que possuem o mesmo material, ainda zelando por encontrar resultados de pressão e vazão que se aproximam da rede real.

Nesta nova rotina, ao fim de cada iteração, as rugosidades calculadas com o uso da Eq. 5 serão submetidas a uma verificação, onde para cada conjunto de materiais será averiguada a existência de valores aberrantes para aquela família de tubulações. Ou seja, para cada material haverá uma lista de rugosidades calculadas, onde será investigada a existência de valores que se distanciam dos demais do mesmo grupo. Esses valores serão então substituídos pela mediana das rugosidades encontradas para este material.

O critério para detectar os valores aberrantes calculados foi baseado na metodologia de detecção de outliers conhecida como a regra do Z-Score Modificado, desenvolvida por Iglewics e Hoaglin (1993) para a detecção de anomalias em amostras de dados levantados.

Este método de detecção de outliers utiliza no cálculo a mediana do desvio absoluto em relação à mediana (MAD), calculado conforme a Eq. 6 .

$$
M A D=\operatorname{mediana}\left|x_{i}-\hat{x}\right|
$$

Em que $x_{i}$ representa os valores da amostra e $\hat{x}$ é a mediana.

O Z-Score modificado $\left(M_{i}\right)$ é calculado com o uso da Eq. 7.

$M_{i}=\frac{0.6745\left(x_{i}-\hat{x}\right)}{M A D}$

Iglewics e Hoaglin (1993) sugerem que pontos com valor de $\mathrm{M}$ maior do que 3.5 ou menor do que -3.5 sejam considerados outliers.

$\mathrm{Na}$ rotina proposta, levou-se em consideração que amostras de menor tamanho apresentam maior dificuldade para se detectarem valores aberrantes. Deste modo, para conjuntos que apresentam até 5 tubulações de mesmo material, os valores considerados como limite para $M$ foram -0.5 e 0.5 . Para conjuntos que possuem entre 6 e 10 tubulações de mesmo material, os valores admissíveis de $M$ adotados se encontram na faixa de -2.0 a 2.0. Por fim, para grupos de 11 ou mais trechos semelhantes, os valores limite admitidos são -3.5 e 3.5 .

O valor limite baixo de $M$ adotado para grupos pequenos de tubulação com mesmo material praticamente obriga todos os trechos deste conjunto a ter uma única rugosidade (a mediana calculada para este grupo), visto que, se em uma determinada rede se encontram apenas 5 ou menos trechos de um certo material, é provável que eles tenham sido instalados em um mesmo momento e que sejam de um mesmo fabricante, reforçando a ideia de que possuem rugosidades semelhantes.

\subsection{Funções Objetivo}

Além do teste da nova rotina de uniformização, este trabalho propõe testar três novas funções objetivo para a calibração, além da já proposta por Rocha, Castro e Araújo (2009) (Eq. 1), a qual será referenciada como $f_{o b j}$. 
Uma das funções propostas consiste na minimização da soma dos quadrados dos erros relativos das pressões, conforme explicitado na Eq. 8.

$$
f_{o b j 2}=\sum_{n N} \frac{\left(P_{O}-P_{C}\right)^{2}}{\left(P_{O}\right)^{2}}
$$

Em que nN é o número de nós da rede, $P_{O}$ é a pressão do nó na Rede Observada e $P_{C}$ é a pressão do nó na Rede Calculada.

Outra função objetivo proposta é uma que minimiza a soma dos quadrados dos erros relativos das vazões, conforme a Eq. 9.

$$
f_{o b j 3}=\sum_{n T} \frac{\left(Q_{O}-Q_{C}\right)^{2}}{\left(Q_{O}\right)^{2}}
$$

Em que $Q_{0}$ é a vazão do trecho na Rede Observada e $Q_{C}$ é a vazão do trecho na Rede Calculada.

Por fim, é proposta também uma função objetivo mais completa, que visa minimizar as diferenças entre pressões, vazões e gradientes hidráulicos da rede observada e calculada, definida na Eq.10.

$$
f_{o b j 4}=f_{o b j 2}+f_{o b j 3}+\sum_{n T} \frac{\left(\nabla H_{O}-\nabla H_{C}\right)^{2}}{\left(\nabla H_{O}\right)^{2}}
$$

É importante frisar que a escolha de determinada função objetivo não implica necessariamente na melhoria dos resultados da medida que teve seu erro minimizado, isto porque as funções minimizam as diferenças entre os dados da Rede Calculada e Observada, e na verificação da qualidade da calibração são comparados os valores calibrados e os reais (gabarito).

\subsection{Rede Calibrada}

A rede escolhida para testar a nova rotina de uniformização, bem como as novas funções objetivo, é uma adaptação da rede proposta por Lansey et al. (2001) e utilizada também por Tabesh, Jasmab e Moeini (2011), representada na Fig. 1.

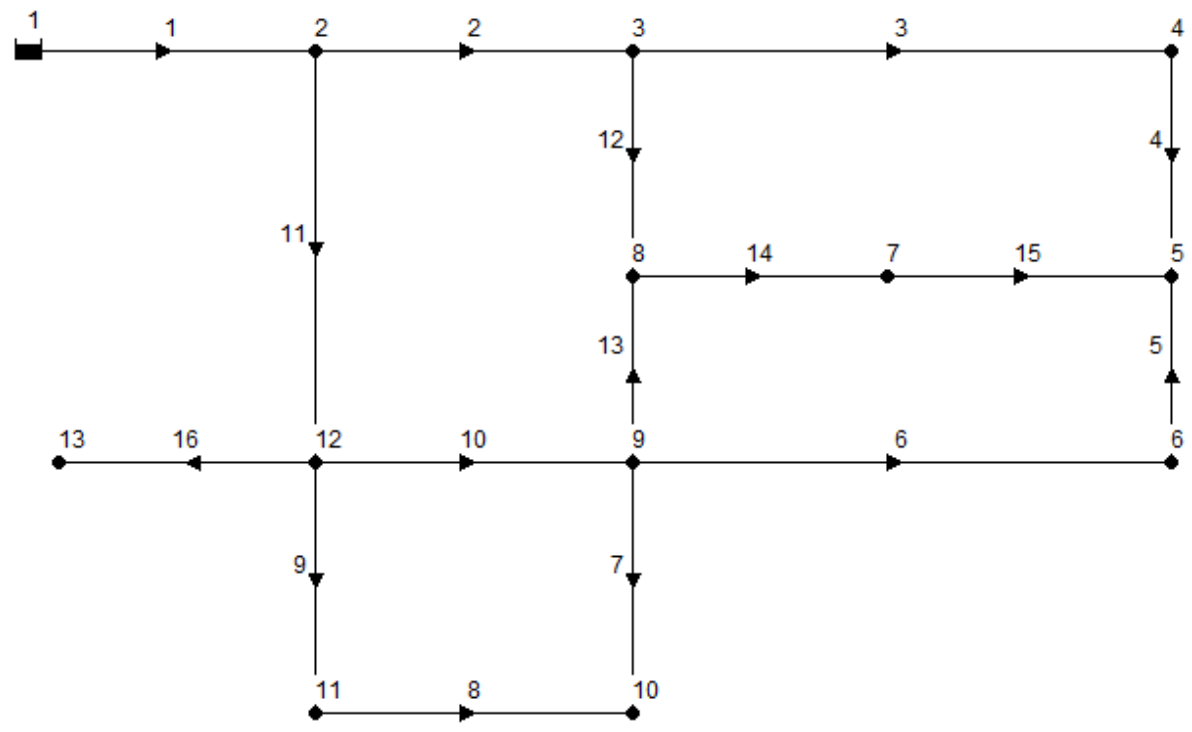

Figura 1 - Rede Lansey et al (2001). 
A rede foi adaptada para se trabalhar com a fórmula universal de Darcy-Weisbach, já que o intuito do trabalho é encontrar as rugosidades absolutas dos trechos.

Por se tratar de uma rede fictícia, são consideradas conhecidas as rugosidades de todas as tubulações, sendo estas chamadas de rugosidades gabarito. Além disso, são conhecidos todos os demais parâmetros necessários para a simula- ção, bem como os dados retornados de pressão nos nós e vazão nos trechos. Os dados de pressão desta rede com as rugosidades corretas (Rede Gabarito) serão utilizados como dados observados para realizar a calibração da Rede Calculada, a qual terá suas rugosidades iniciais adotadas como $0.06 \mathrm{~mm}$ para todos os trechos. Os dados referentes às simulações da Rede Gabarito e Calculada se encontram nas Tabelas 1 e 2.

Tabela 1 - Dados dos trechos da Rede Gabarito e Calculada (não calibrada).

\begin{tabular}{|c|c|c|c|c|c|c|}
\hline \multirow{2}{*}{ Trecho } & \multirow{2}{*}{ Comprimento (m) } & \multirow{2}{*}{$\underset{(\mathrm{mm})}{D}$} & \multicolumn{2}{|c|}{ Rede Gabarito } & \multicolumn{2}{|c|}{ Rede Calculada } \\
\hline & & & $\varepsilon(\mathrm{mm})$ & Vazão (L/s) & $\varepsilon(\mathrm{mm})$ & Vazão (L/s) \\
\hline 1 & 3048.0 & 610 & 2.00 & 267.0000 & 0.06 & 267.0000 \\
\hline 2 & 1524.0 & 457 & 2.00 & 148.0687 & 0.06 & 147.6574 \\
\hline 3 & 1524.0 & 406 & 1.25 & 62.5712 & 0.06 & 62.8961 \\
\hline 4 & 1676.4 & 356 & 1.25 & 21.5712 & 0.06 & 21.8961 \\
\hline 5 & 1066.8 & 305 & 0.10 & 7.3600 & 0.06 & 5.9506 \\
\hline 6 & 1676.4 & 356 & 0.10 & 38.3600 & 0.06 & 36.9506 \\
\hline 7 & 1371.6 & 305 & 4.00 & 21.5548 & 0.06 & 21.4422 \\
\hline 8 & 762.0 & 152 & 4.00 & 5.4452 & 0.06 & 5.5578 \\
\hline 9 & 1066.8 & 305 & 4.00 & 27.4452 & 0.06 & 27.5578 \\
\hline 10 & 670.6 & 381 & 4.00 & 74.4861 & 0.06 & 74.7848 \\
\hline 11 & 1981.2 & 457 & 2.00 & 118.9313 & 0.06 & 119.3426 \\
\hline 12 & 1524.0 & 356 & 1.25 & 41.4975 & 0.06 & 40.7613 \\
\hline 13 & 1676.4 & 305 & 0.10 & 14.5713 & 0.06 & 16.3920 \\
\hline 14 & 914.4 & 356 & 1.25 & 32.0688 & 0.06 & 33.1534 \\
\hline 15 & 1219.2 & 305 & 1.25 & 8.0688 & 0.06 & 9.1534 \\
\hline 16 & 1219.2 & 406 & 4.00 & 17.0000 & 0.06 & 17.0000 \\
\hline
\end{tabular}

Tabela 2 - Dados dos nós da Rede Gabarito e Calculada (não calibrada).

\begin{tabular}{|c|c|c|c|c|}
\hline \multirow{2}{*}{ Nó } & \multirow{2}{*}{$\begin{array}{l}\text { Cota } \\
(\mathrm{m})\end{array}$} & \multirow{2}{*}{$\begin{array}{l}\text { Consumo } \\
\text { (L/s) }\end{array}$} & \multirow{2}{*}{$\begin{array}{l}\text { Rede Gabarito } \\
\text { Pressão (m) }\end{array}$} & \multirow{2}{*}{$\begin{array}{c}\text { Rede Calculada } \\
\text { Pressão (m) }\end{array}$} \\
\hline & & & & \\
\hline 2 & 45.7 & 0 & 64.3280 & 67.0603 \\
\hline 3 & 48.7 & 44 & 57.2368 & 61.9714 \\
\hline 4 & 50.3 & 41 & 54.4205 & 59.6113 \\
\hline 5 & 48.7 & 37 & 55.6918 & 60.9822 \\
\hline 6 & 45.7 & 31 & 58.7358 & 64.0120 \\
\hline 7 & 47.2 & 24 & 57.2712 & 62.5552 \\
\hline 8 & 44.2 & 24 & 60.6604 & 65.8217 \\
\hline 9 & 42.7 & 0 & 62.3981 & 67.6087 \\
\hline 10 & 39.6 & 27 & 64.6512 & 70.3258 \\
\hline 11 & 41.1 & 22 & 64.4236 & 69.3685 \\
\hline 12 & 44.2 & 0 & 62.3874 & 66.7404 \\
\hline 13 & 39.6 & 17 & 66.8839 & 71.2846 \\
\hline
\end{tabular}


Para as calibrações realizadas neste trabalho, foi estabelecido um número de 100 iterações, sem determinar um valor objetivo como critério de parada, de modo que permitisse a comparação entre os resultados encontrados pelas diferentes funções objetivo. Como resultado final do método, foi considerada a iteração com menor valor calculado para a função objetivo em cada calibração.

A Fig. 2 esquematiza o roteiro utilizado nas calibrações, utilizando a rotina de uniformização.

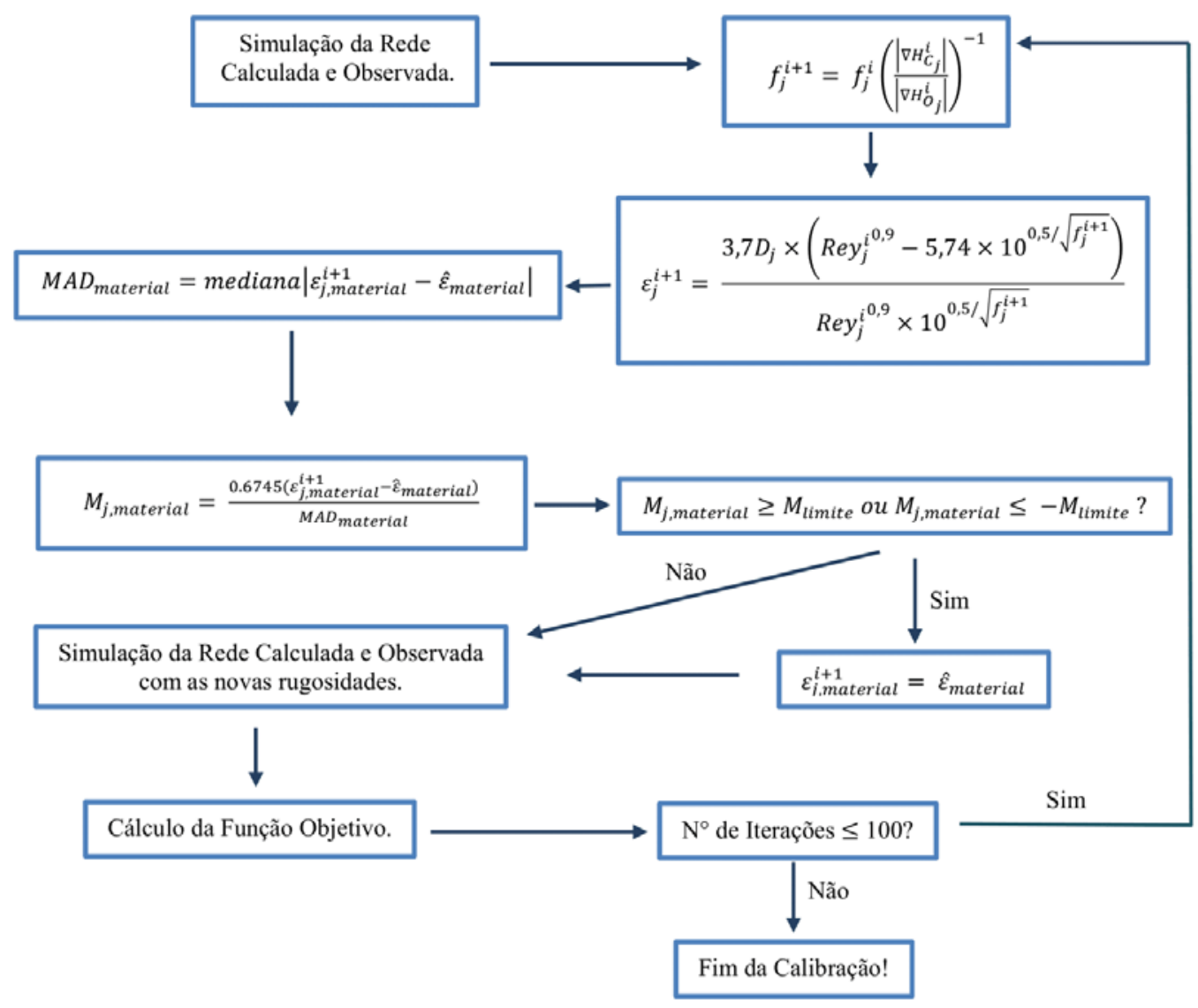

Figura 2 - Fluxograma da calibração com o uso da nova rotina de uniformização.

Para o uso da rotina de uniformização, admitiuse que a rede possui quatro grupos de materiais, onde o primeiro grupo é composto pelos trechos com rugosidade gabarito igual a $2 \mathrm{~mm}$ (trechos 1,2 e 11), o segundo grupo pelos trechos com rugosidade gabarito igual a $1.25 \mathrm{~mm}$ (trechos 3 , $4,12,14$ e 15), o terceiro grupo com rugosidade gabarito igual a $0.10 \mathrm{~mm}$ (trechos 5,6 e 13) e o quarto grupo com rugosidade gabarito igual a 4 $\mathrm{mm}$ (trechos 7, 8, 9, 10 e 16).
Neste trabalho, realizou-se inicialmente a calibração da Rede Calculada considerando todos os dados de pressão conhecidos, retirados da simulação da rede gabarito. Foram testadas as 4 funções objetivo, com e sem a utilização da nova rotina de uniformização, totalizando 8 calibrações. Em seguida, repetiu-se o processo, admitindo-se apenas $50 \%$ dos dados de pressão conhecidos e por fim apenas $25 \%$ dos dados de pressão conhecidos, totalizando 24 calibrações em todo o trabalho. 


\section{RESULTADOS E DISCUSSÕES}

Neste trabalho, a apresentação dos resultados foi dividida em 3 partes, uma para cada configuração de pressões conhecidas na calibração. Para a análise, foram comparados os valores de rugosidades, pressões e vazões obtidos nas calibrações com os respectivos valores da Rede Gabarito, dando ênfase à rugosidade, que é o parâmetro que está sendo calibrado.

\subsection{Calibrações com 100\% das pressões conhecidas}

A Tabela 3 e a Fig. 3 apresentam os resultados obtidos para as rugosidades calibrando-se com as pressões de todos os nós conhecidas, sem a utilização da rotina de uniformização e testando as 4 funções objetivo propostas.

Tabela 3 - Calibração com 100\% das pressões conhecidas, sem a rotina de uniformização.

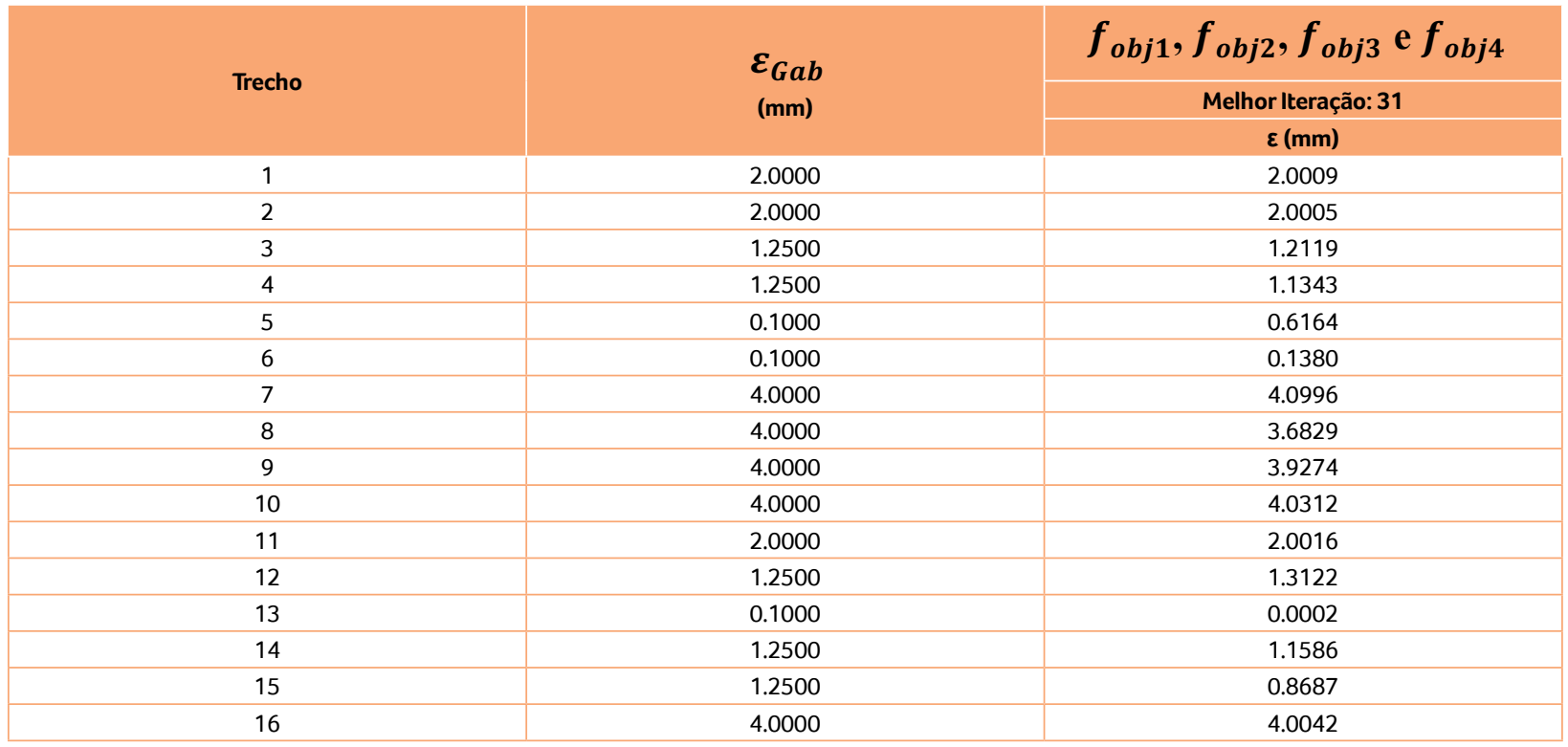

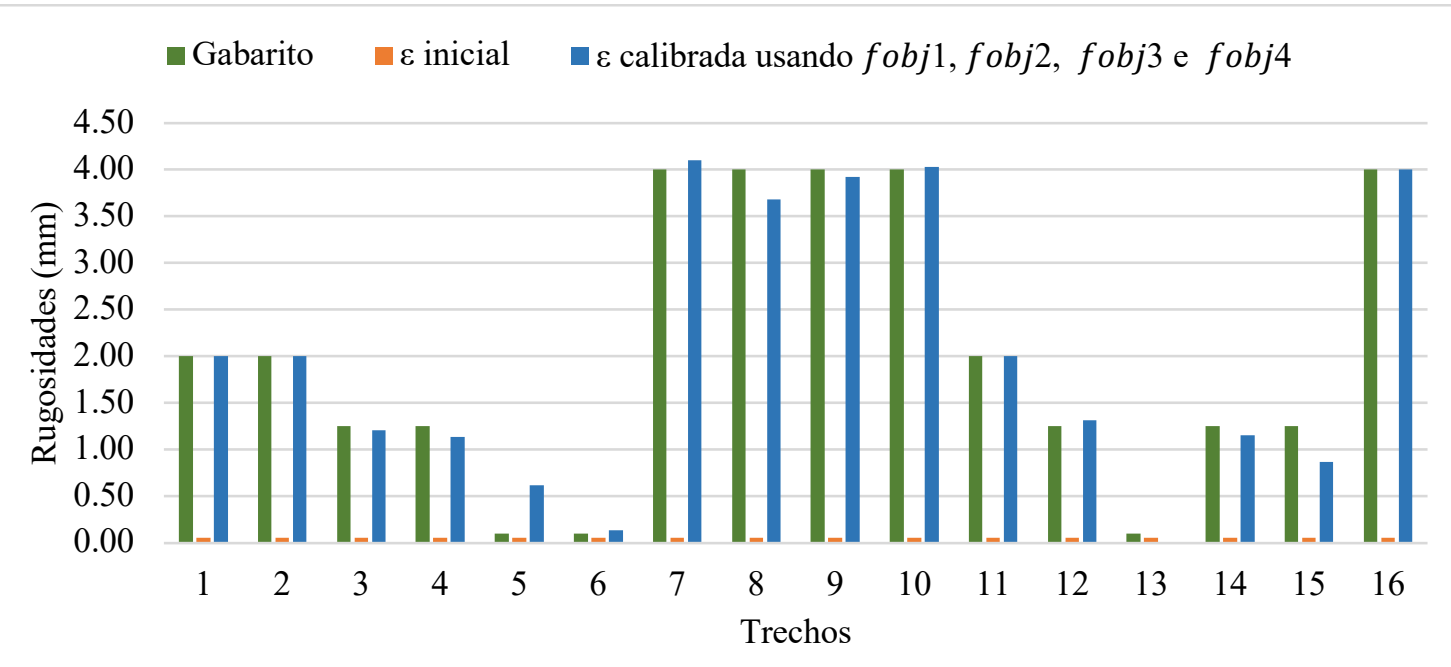

Figura 3 - Gráfico das rugosidades calibradas com 100\% das pressões conhecidas, sem a utilização da rotina de uniformização. 
As rugosidades iniciais da Rede Calculada foram colocadas para melhor visualizar a otimização que o método oferece.

Observou-se que as calibrações realizadas com as pressões conhecidas em todos os nós, sem a utilização da nova rotina de uniformização, retornaram como resultado a mesma iteração para as 4 funções objetivo, ou seja, a mesma configuração de rugosidades em todas as calibrações. Observando a Tabela 3 e a Fig. 3, notou-se que os resultados encontrados foram satisfatórios, com exceção dos trechos 5 e 13, que obtiveram resul- tados piores do que o valor inicial de $0.06 \mathrm{~mm}$. Além disso, reparou-se que o valor encontrado para o trecho 13 possui uma ordem de grandeza muito baixa $(0.0002 \mathrm{~mm})$, valor este que o método deveria notar ser muito baixo para aquele grupo de tubulações.

Os resultados obtidos de vazões e pressões para as calibrações com $100 \%$ das pressões conhecidas, sem a rotina de uniformização, foram resumidos na Fig. 4, que apresenta os erros relativos médios de cada calibração para estes dois dados, bem como para a rugosidade calibrada.

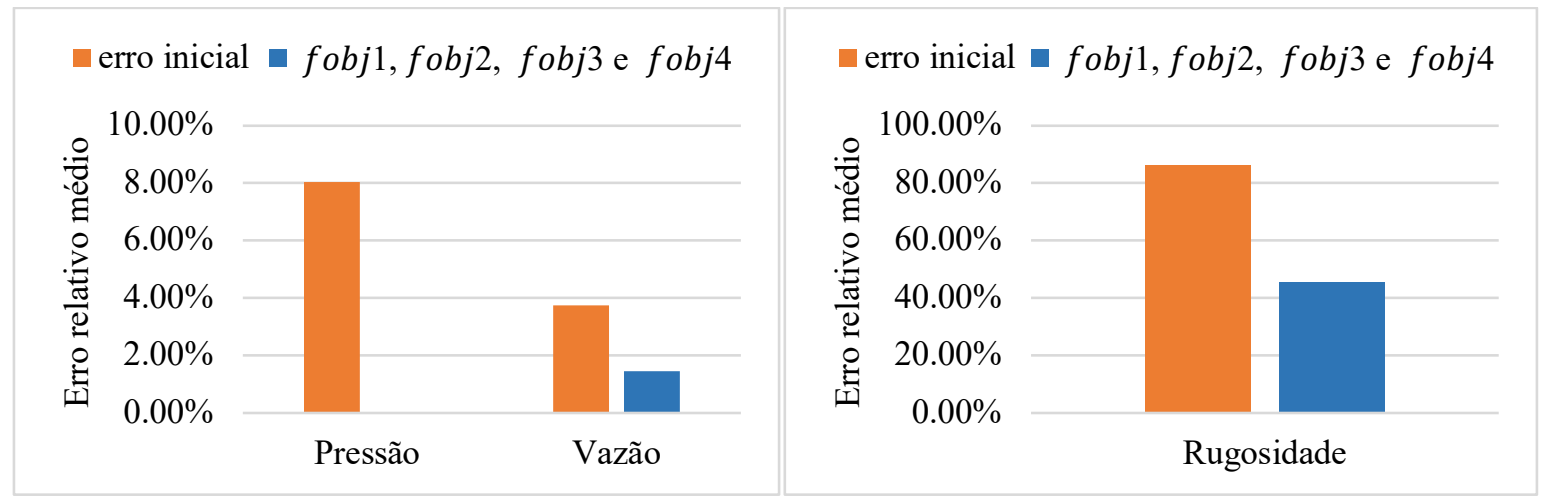

Figura 4 - Erro relativo médio das pressões, vazões e rugosidades para a calibração com 100\% das pressões conhecidas, sem a rotina de uniformização.

Nestas calibrações, notou-se que utilizando qualquer função objetivo os resultados alcançados foram melhores do que o valor inicial. 0 erro relativo médio para as rugosidades, que era de $86.22 \%$ para o valor inicial, caiu para $45.16 \%$. Apesar de esse valor ser consideravelmente alto, vale notar que as rugosidades apresentam valores muito baixos e pequenas diferenças resultam em grandes erros relativos. Nesse caso, o erro absoluto médio calculado para as rugosidades foi de apenas $0.12 \mathrm{~mm}$. Quanto às pressões, ob- servou-se que as calibrações também melhoraram os resultados, diminuindo o erro relativo médio de $8 \%$ para $0.0025 \%$. Para as vazões também houve uma melhoria, onde o erro relativo médio caiu de $3.75 \%$ para $1.44 \%$.

A Tabela 4 e a Fig. 5 apresentam os resultados obtidos para as calibrações utilizando também todos os dados de pressões nos nós conhecidos, mas desta vez com o uso da nova rotina de uniformização das rugosidades. 
Tabela 4 - Calibração com 100\% das pressões conhecidas, com a rotina de uniformização.

\begin{tabular}{|c|c|c|c|c|}
\hline \multirow{3}{*}{ Trecho } & \multirow{3}{*}{$\underset{(\mathrm{mm})}{\mathcal{E}_{G a b}}$} & $f_{o b j 1}$ & \multirow{2}{*}{$\begin{array}{c}f_{o b j 2} \\
\text { Melhor Iteração: } 5\end{array}$} & \multirow{2}{*}{$\begin{array}{l}\boldsymbol{f}_{\text {obj3 }} \text { e } \boldsymbol{f}_{\text {obj4 }} \\
\text { Melhor Iteração: } 53\end{array}$} \\
\hline & & Melhor Iteração: 100 & & \\
\hline & & $\varepsilon(\mathrm{mm})$ & $\varepsilon(\mathrm{mm})$ & $\varepsilon(\mathrm{mm})$ \\
\hline 1 & 2.0000 & 2.0009 & 2.0009 & 2.0009 \\
\hline 2 & 2.0000 & 2.0009 & 2.0009 & 2.0009 \\
\hline 3 & 1.2500 & 1.2509 & 1.2413 & 1.2509 \\
\hline 5 & 0.1000 & 0.1026 & 0.1060 & 0.1026 \\
\hline 6 & 0.1000 & 0.1026 & 0.1060 & 0.1026 \\
\hline 7 & 4.0000 & 4.0024 & 4.0042 & 4.0024 \\
\hline 8 & 4.0000 & 4.0024 & 4.0042 & 4.0024 \\
\hline 9 & 4.0000 & 4.0024 & 4.0040 & 4.0024 \\
\hline 10 & 4.0000 & 4.0024 & 4.0042 & 4.0024 \\
\hline 12 & 1.2500 & 1.2509 & 1.2413 & 1.2509 \\
\hline 13 & 0.1000 & 0.1026 & 0.1060 & 0.1026 \\
\hline 14 & 1.2500 & 1.2509 & 1.2413 & 1.2509 \\
\hline 15 & 1.2500 & 1.2509 & 1.2413 & 1.2509 \\
\hline 16 & 4.0000 & 4.0024 & 4.0042 & 4.0024 \\
\hline
\end{tabular}

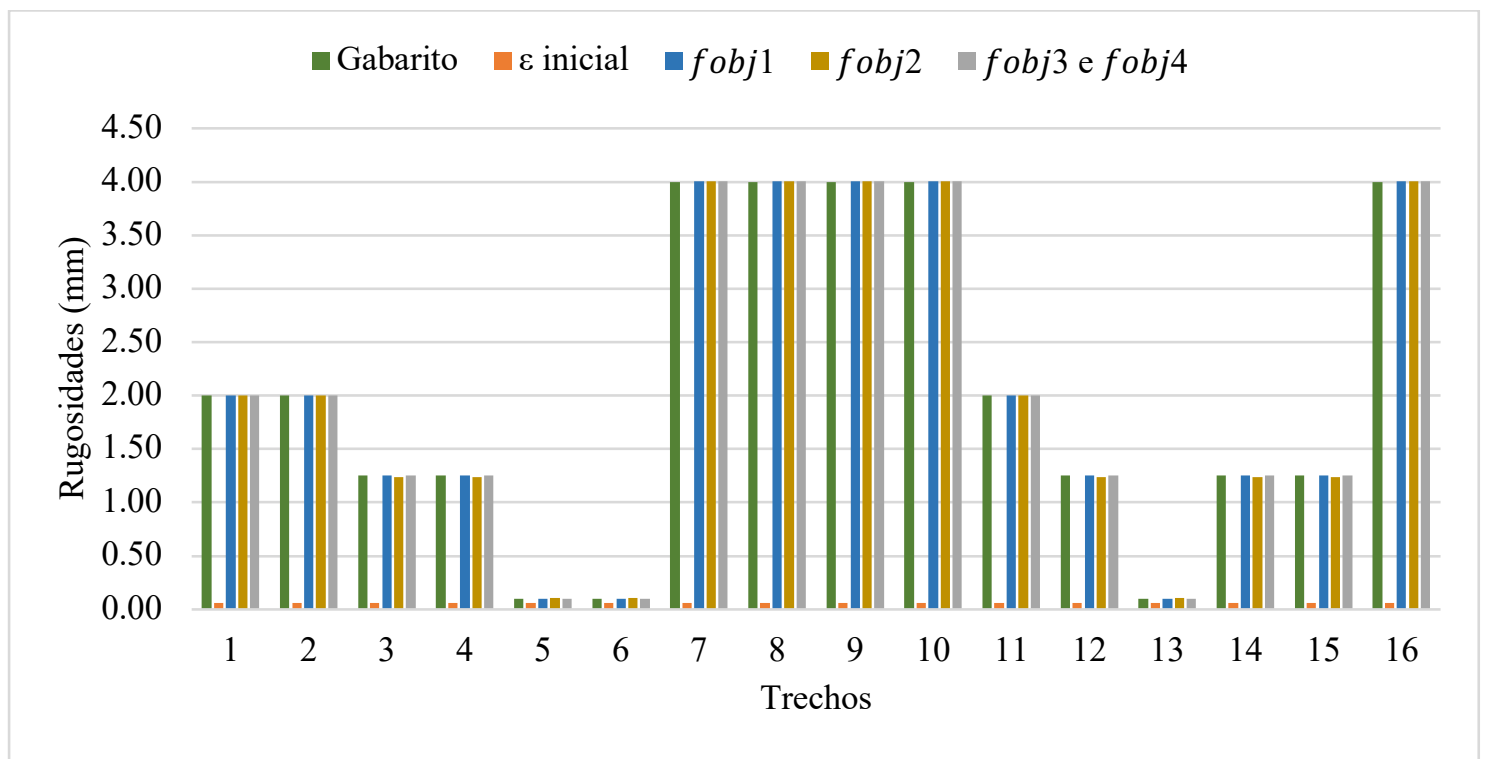

Figura 5 - Gráfico das rugosidades calibradas com 100\% das pressões conhecidas, com a rotina de uniformização.

Examinando a Tabela 4 e a Fig. 5, observou-se que nessas calibrações os resultados encontrados foram superiores àqueles onde não foi utilizada a rotina de uniformização. Notou-se que, apesar de retornarem diferentes iterações, os resultados encontrados com o uso das dife- rentes funções objetivo se assemelham, o que sugere que neste caso o método converge e se estabiliza rapidamente.

A Fig. 6 apresenta os erros relativos médios encontrados para essas calibrações referentes às pressões, vazões e rugosidades. 


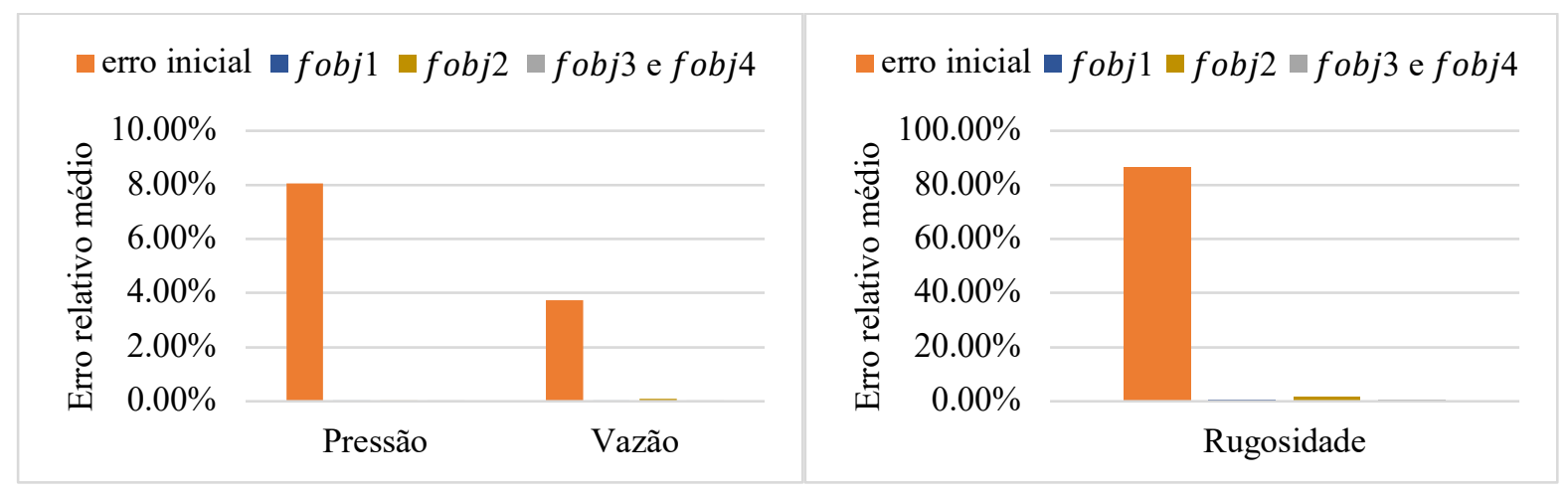

Figura 6 - Erro relativo médio das pressões, vazões e rugosidades para a calibração com $100 \%$ das pressões conhecidas, com a rotina de uniformização.

Analisando a Fig. 6 pôde-se observar que os erros relativos médios para todos os parâmetros de referência foram visivelmente mais baixos do que os encontrados nas calibrações anteriores, o que demonstra uma melhoria nos resultados quando utilizada a rotina de uniformização das rugosidades. Apesar de todas as funções objetivo retornarem valores muito próximos, destacaram-se as funções 1, 3 e 4, que apresentaram um erro relativo médio de $0.54 \%$ para as rugosidades, $0.0024 \%$ para as pressões e $0.03 \%$ para as vazões.

\subsection{Calibrações com $50 \%$ das pressões conhecidas}

Nessas calibrações, foram admitidas conhecidas as pressões nos nós 2, 4, 6, 8, 10 e 12. Os critérios utilizados na escolha desses 6 nós foram suas posições afastadas e que abrangem toda a rede. A Tabela 5 e a Fig. 7 apresentam os resultados obtidos para as rugosidades nestas calibrações, sem a utilização da rotina de uniformização.

Tabela 5 - Calibração com 50\% das pressões conhecidas, sem a rotina de uniformização.

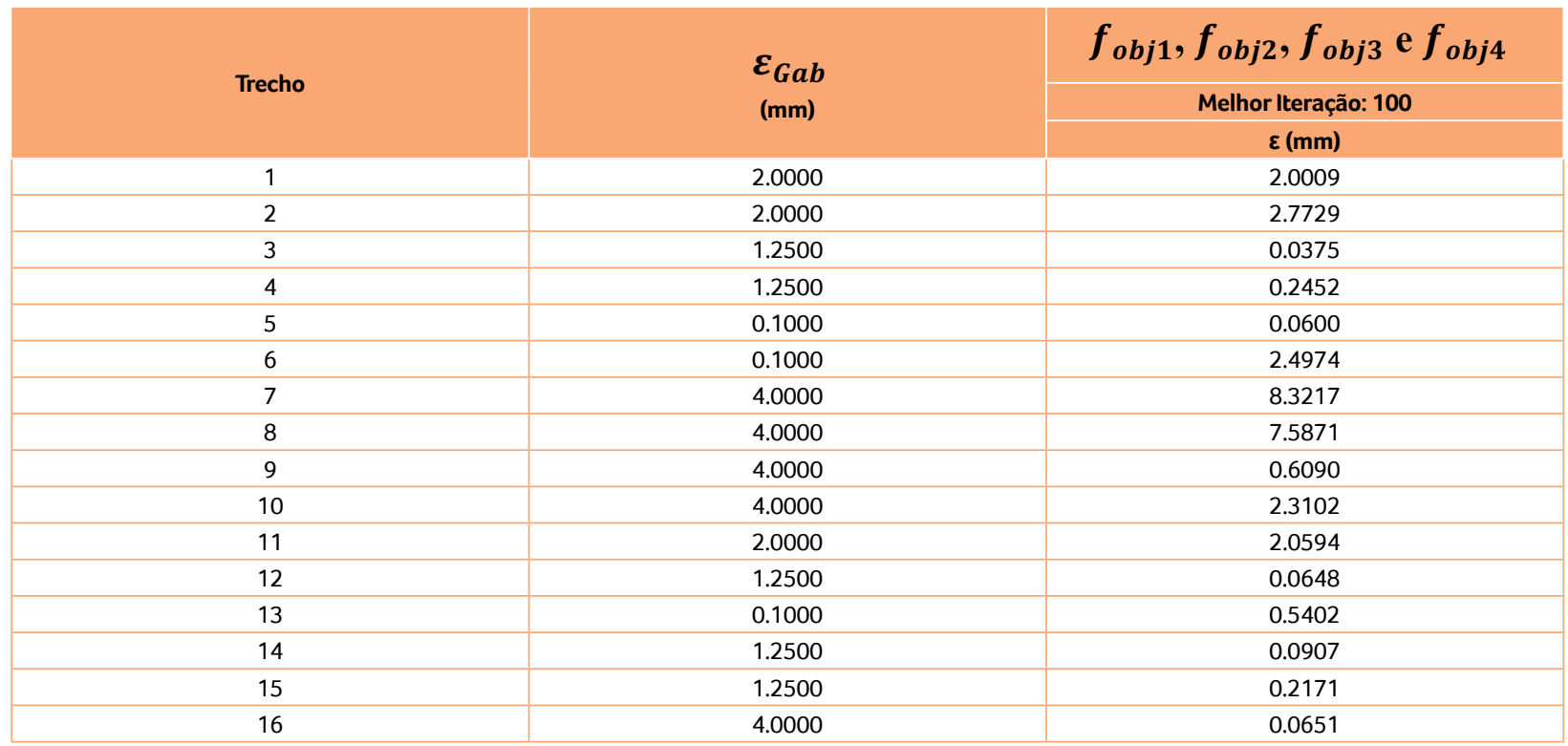




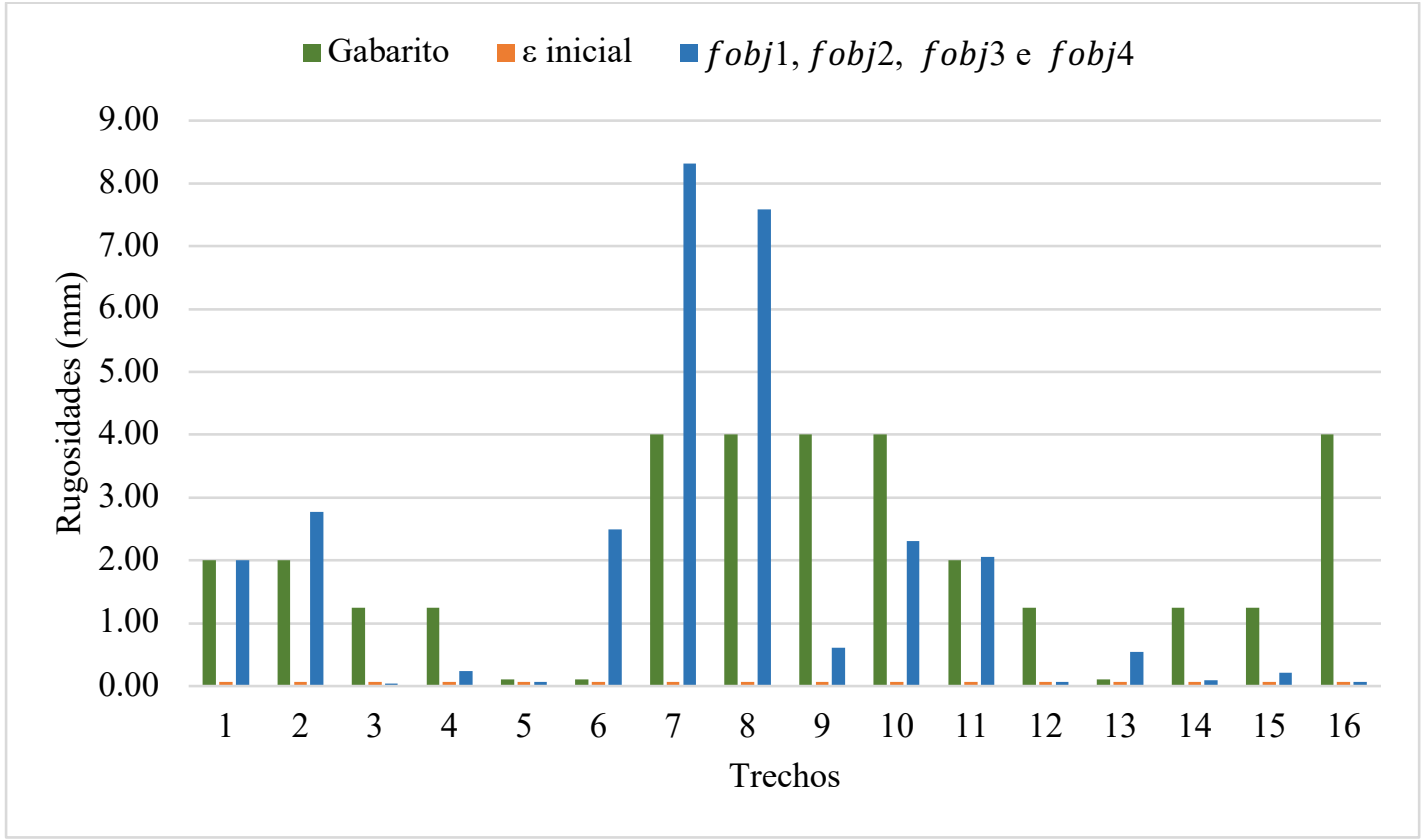

Figura 7 - Gráfico das rugosidades calibradas com 50\% das pressões conhecidas, sem a rotina de uniformização.

Analisando a Tabela 5 e a Fig. 7 observou-se uma queda expressiva na qualidade dos resultados quando comparados aos obtidos pelas calibrações que utilizaram $100 \%$ das pressões conhecidas. Mais uma vez, observou-se que o não uso da rotina de uniformização proposta permitiu que trechos que deveriam possuir a mesma rugosidade apresentassem valores muito discrepantes para esse parâmetro, o que contribuiu para os maus resultados obtidos.

Os resultados obtidos de vazões, pressões e rugosidades para as calibrações com $50 \%$ das pressões conhecidas, sem a rotina de uniformização, foram sintetizados na Fig. 8, na forma de erros relativos médios.

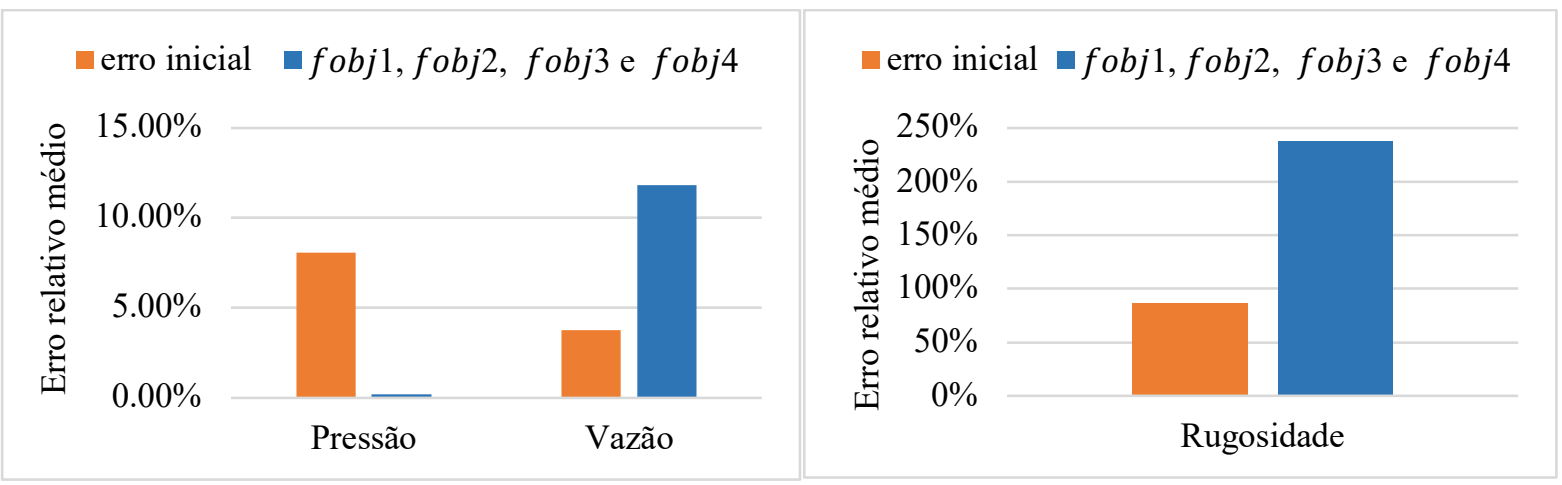

Figura 8 - Erro relativo médio das pressões, vazões e rugosidades para a calibração com $50 \%$ das pressões conhecidas, sem a rotina de uniformização.

A Fig. 8 revelou que o método foi eficiente quanto às pressões encontradas após a correção das ru- gosidades, diminuindo o erro relativo médio para $0.18 \%$. No entanto, o erro calculado para as vazões 
após as calibrações foi de $11.82 \%$, apresentando um aumento com relação à configuração inicial. 0 erro relativo médio calculado para as rugosidades também aumentou, subindo para $236.87 \%$.
A Tabela 6 e a Fig. 9 apresentam as rugosidades encontradas nas calibrações com apenas 50\% dos nós com pressões conhecidas, desta vez com a utilização da nova rotina de uniformização.

Tabela 6 - Calibração com 50\% das pressões conhecidas, com a rotina de uniformização.

\begin{tabular}{|c|c|c|c|c|}
\hline \multirow{3}{*}{ Trecho } & \multirow{3}{*}{$\begin{array}{c}\mathcal{E}_{G a b} \\
(\mathrm{~mm})\end{array}$} & $f_{o b j 1}$ & $f_{o b j 2}$ & $f_{o b j 3} e f_{o b j 4}$ \\
\hline & & Melhor Iteração: 43 & Melhor Iteração: 52 & Melhor Iteração: 41 \\
\hline & & $\varepsilon(\mathrm{mm})$ & $\varepsilon(\mathrm{mm})$ & $\varepsilon(\mathrm{mm})$ \\
\hline 1 & 2.0000 & 2.0009 & 2.0009 & 2.0023 \\
\hline 2 & 2.0000 & 2.0009 & 2.0009 & 2.0023 \\
\hline 3 & 1.2500 & 1.2504 & 1.2328 & 1.2476 \\
\hline 4 & 1.2500 & 1.2504 & 1.2328 & 1.2476 \\
\hline 5 & 0.1000 & 0.1042 & 0.1128 & 0.0996 \\
\hline 6 & 0.1000 & 0.1042 & 0.1128 & 0.0996 \\
\hline 7 & 4.0000 & 4.0050 & 4.0114 & 4.0106 \\
\hline 8 & 4.0000 & 4.0050 & 4.0114 & 4.0106 \\
\hline 9 & 4.0000 & 4.0050 & 4.0114 & 4.0106 \\
\hline 10 & 4.0000 & 4.0050 & 4.0114 & 4.0124 \\
\hline 11 & 2.0000 & 2.0009 & 2.0009 & 2.0023 \\
\hline 12 & 1.2500 & 1.2504 & 1.2328 & 1.2476 \\
\hline 13 & 0.1000 & 0.1042 & 0.1128 & 0.0996 \\
\hline 14 & 1.2500 & 1.2504 & 1.2320 & 1.2493 \\
\hline 15 & 1.2500 & 1.2504 & 1.2328 & 1.2476 \\
\hline 16 & 4.0000 & 4.0050 & 4.0114 & 4.0106 \\
\hline
\end{tabular}

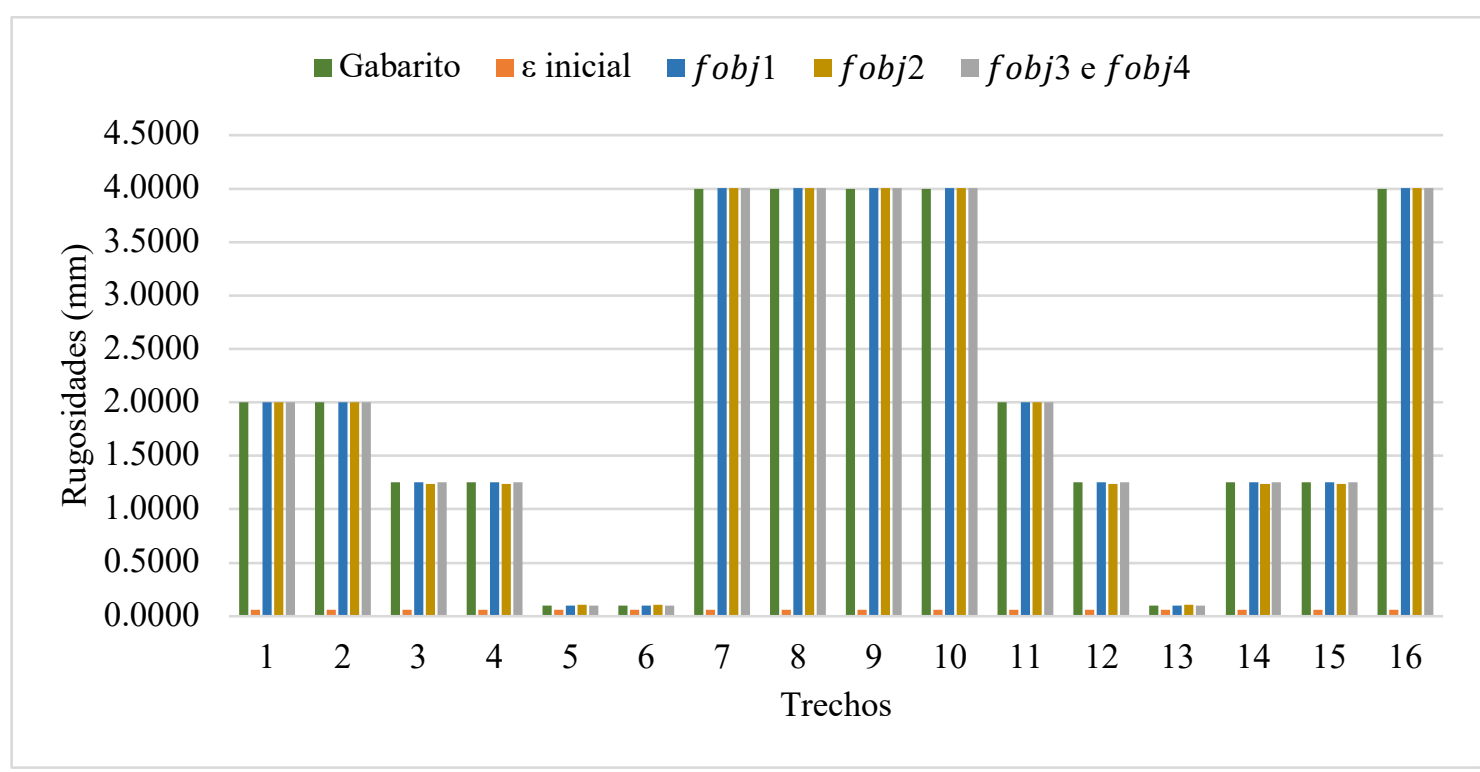

Figura 9 - Gráfico das rugosidades calibradas com 50\% das pressões conhecidas, com a rotina de uniformização.

A Tabela 6 e a Fig. 9 demonstram que as calibrações que utilizaram a nova rotina de uniformização seguiram apresentando excelentes resultados. No- tou-se também que, mesmo retornando diferentes iterações, todas as funções objetivo apresentaram resultados semelhantes e satisfatórios. 
A Fig. 10 apresenta os erros relativos médios encontrados para as calibrações com $50 \%$ das pressões conhecidas, com o uso da rotina de uniformização.

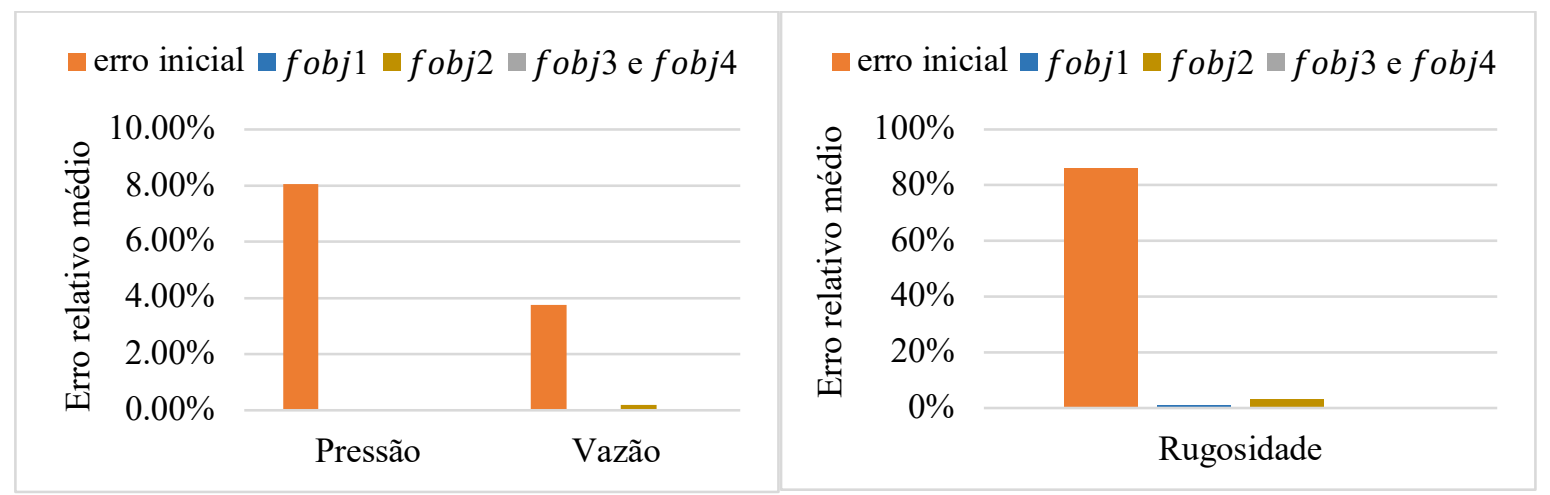

Figura 10 - Erro relativo médio das pressões, vazões e rugosidades para a calibração com 50\% das pressões conhecidas, com a rotina de uniformização.

A análise da Fig. 10 evidenciou que as calibrações que utilizaram a rotina de uniformização proposta retornaram excelentes valores de pressões e vazões, com erros relativos médios inferiores a $0.0052 \%$ e $0.18 \%$ respectivamente, com o uso de qualquer uma das funções objetivo. Esses resultados são consequências diretas dos bons valores encontrados para as rugosidades, que apresentaram erros inferiores a $2.94 \%$ para todas essas calibrações.

\subsection{Calibrações com 25\% das pressões conhecidas}

Por fim, admitiram-se como conhecidas apenas as pressões nos nós 2, 6 e 10. Os critérios utilizados na escolha desses 3 nós foram os mesmos utilizados nas calibrações anteriores. A Tabela 7 e a Fig. 11 apresentam os resultados obtidos para as rugosidades nestas calibrações, sem o uso da rotina de uniformização.

Tabela 7 - Calibração com $25 \%$ das pressões conhecidas, sem a rotina de uniformização.

\begin{tabular}{|c|c|c|c|c|c|}
\hline \multirow{3}{*}{ Trecho } & \multirow{3}{*}{$\underset{(\mathrm{mm})}{\mathcal{E}_{G a b}}$} & $f_{o b j 1}$ & $f_{o b j 2}$ & $f_{o b j 3}$ & $f_{o b j 4}$ \\
\hline & & Melhor Iteração: 95 & Melhor Iteração: 11 & Melhor Iteração: 90 & Melhor Iteração: 91 \\
\hline & & $\varepsilon(\mathrm{mm})$ & $\varepsilon(\mathrm{mm})$ & $\varepsilon(\mathrm{mm})$ & $\varepsilon(\mathrm{mm})$ \\
\hline 1 & 2.0000 & 2.0009 & 2.0009 & 2.0009 & 2.0009 \\
\hline 2 & 2.0000 & 2.2555 & 2.2242 & 2.2526 & 2.2528 \\
\hline 3 & 1.2500 & 0.2447 & 0.3639 & 0.2468 & 0.2460 \\
\hline 4 & 1.2500 & 0.0001 & 0.0038 & 0.0001 & 0.0001 \\
\hline 5 & 0.1000 & 11.9614 & 0.0600 & 0.0600 & 11.9614 \\
\hline 6 & 0.1000 & 7.0664 & 5.4409 & 7.1040 & 7.1179 \\
\hline 7 & 4.0000 & 10.2139 & 10.3513 & 10.2173 & 10.2163 \\
\hline 8 & 4.0000 & 10.7133 & 10.5323 & 10.7104 & 10.7123 \\
\hline 9 & 4.0000 & 0.7519 & 0.7471 & 0.7519 & 0.7519 \\
\hline 10 & 4.0000 & 3.5436 & 3.4628 & 3.5467 & 3.5472 \\
\hline 11 & 2.0000 & 1.8376 & 1.8045 & 1.8387 & 1.8390 \\
\hline 12 & 1.2500 & 0.0633 & 0.0747 & 0.0637 & 0.0637 \\
\hline 13 & 0.1000 & 0.1585 & 0.3349 & 0.1553 & 0.1542 \\
\hline 14 & 1.2500 & 0.1077 & 0.1918 & 0.1067 & 0.1062 \\
\hline 15 & 1.2500 & 0.2597 & 0.7460 & 0.2548 & 0.2526 \\
\hline 16 & 4.0000 & 0.0651 & 0.0651 & 0.0651 & 0.0651 \\
\hline
\end{tabular}




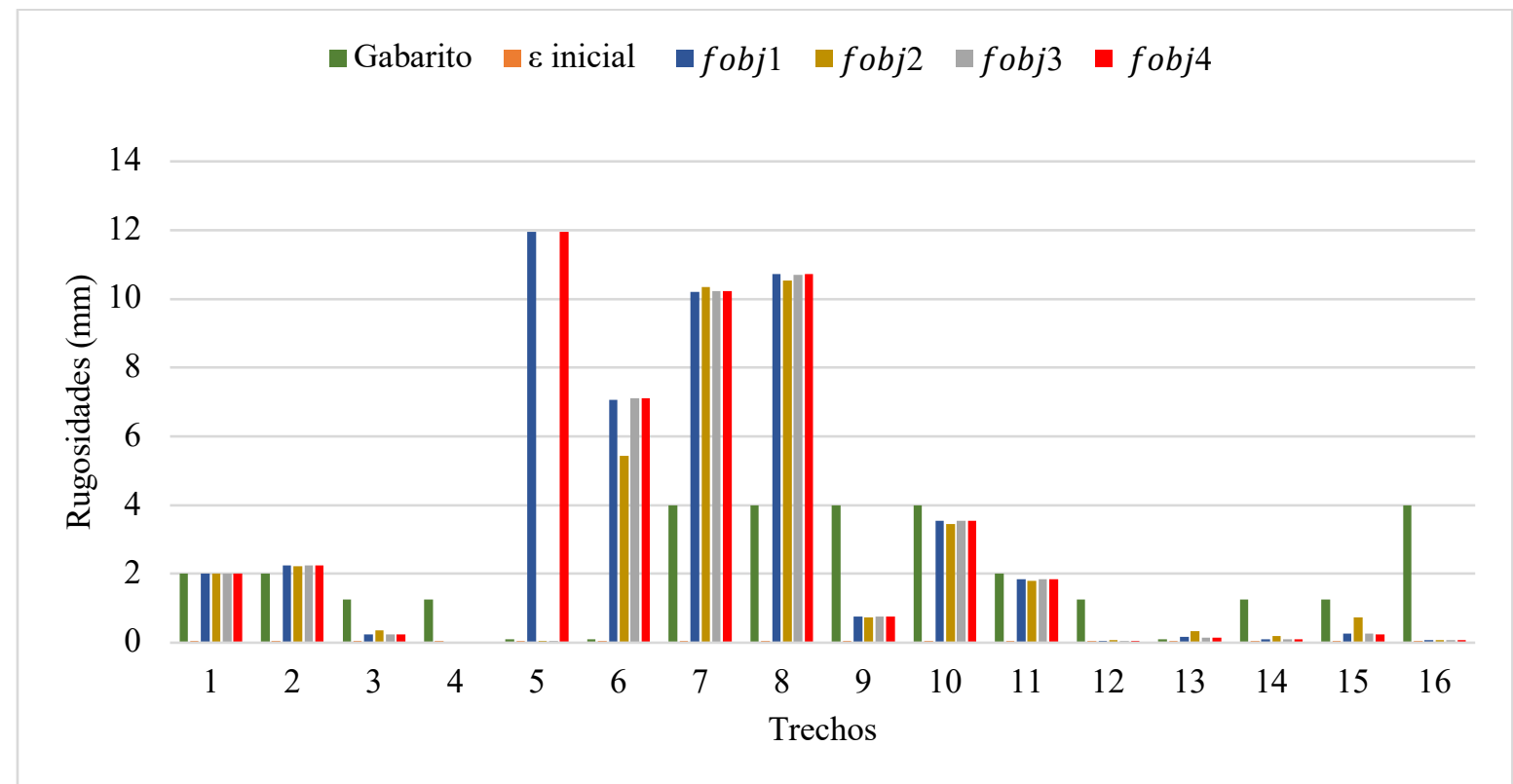

Figura 11 - Gráfico das rugosidades calibradas com 25\% das pressões conhecidas, sem a rotina de uniformização.

Analisando os resultados da Tabela 7 e a Fig. 11 , notou-se uma grande queda na qualidade das calibrações quando comparadas às realizadas com um maior número de pressões conhecidas. Pôde-se notar que para todas as funções objetivo há vários trechos com erros grosseiros para as rugosidades, e que trechos que deveriam possuir o mesmo valor para esse parâmetro se apresentam com valores completamente diferentes.

A Fig. 12 apresenta os erros relativos médios destas calibrações referentes às pressões, vazões e rugosidades. $\square$ erro inicial $\square$ fobj $1 \square$ fobj2 $\square$ fobj3 $\square$ fobj4

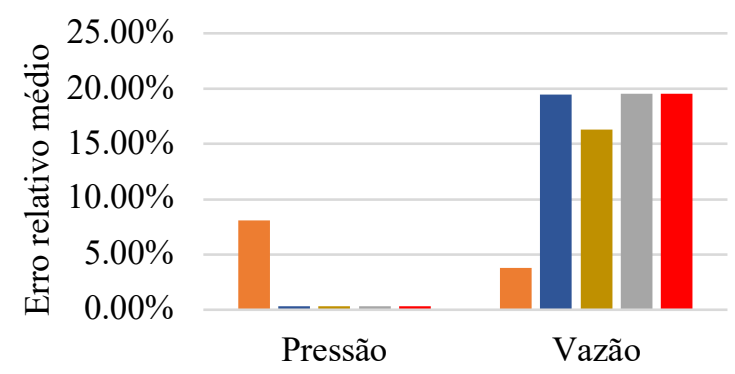

$\square$ erro inicial $\square$ fobj $1 \square$ fobj2 $\square$ fobj3 $\square$ fobj4

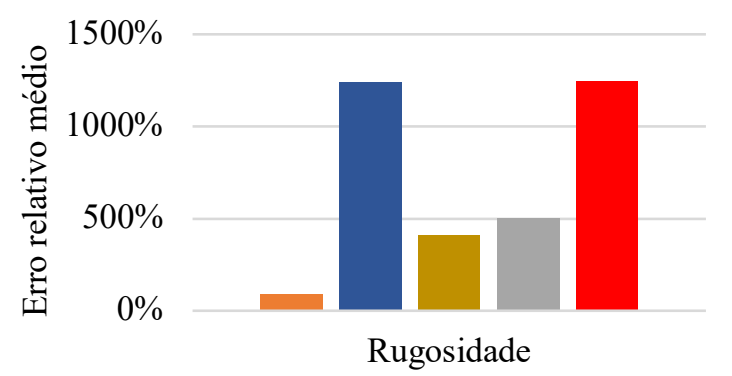

Figura 12 - Erro relativo médio das pressões, vazões e rugosidades para a calibração com 25\% das pressões conhecidas, sem a rotina de uniformização.

A Fig. 12 mostra que as calibrações, realizadas com apenas $25 \%$ dos nós com as pressões conhecidas, melhoraram os valores das pressões em relação à configuração inicial, diminuindo o erro relativo médio para valores inferiores a $0.3 \%$ em todos os casos. No entanto, os erros encontrados para as vazões aumentaram, assim como os erros para as rugosidades. 
A Tabela 8 e a Fig. 13 apresentam os resultados encontrados nas calibrações com $25 \%$ dos nós com pressões conhecidas, utilizando a nova rotina de uniformização.

Tabela 8 - Calibração com 25\% das pressões conhecidas, com a rotina de uniformização.

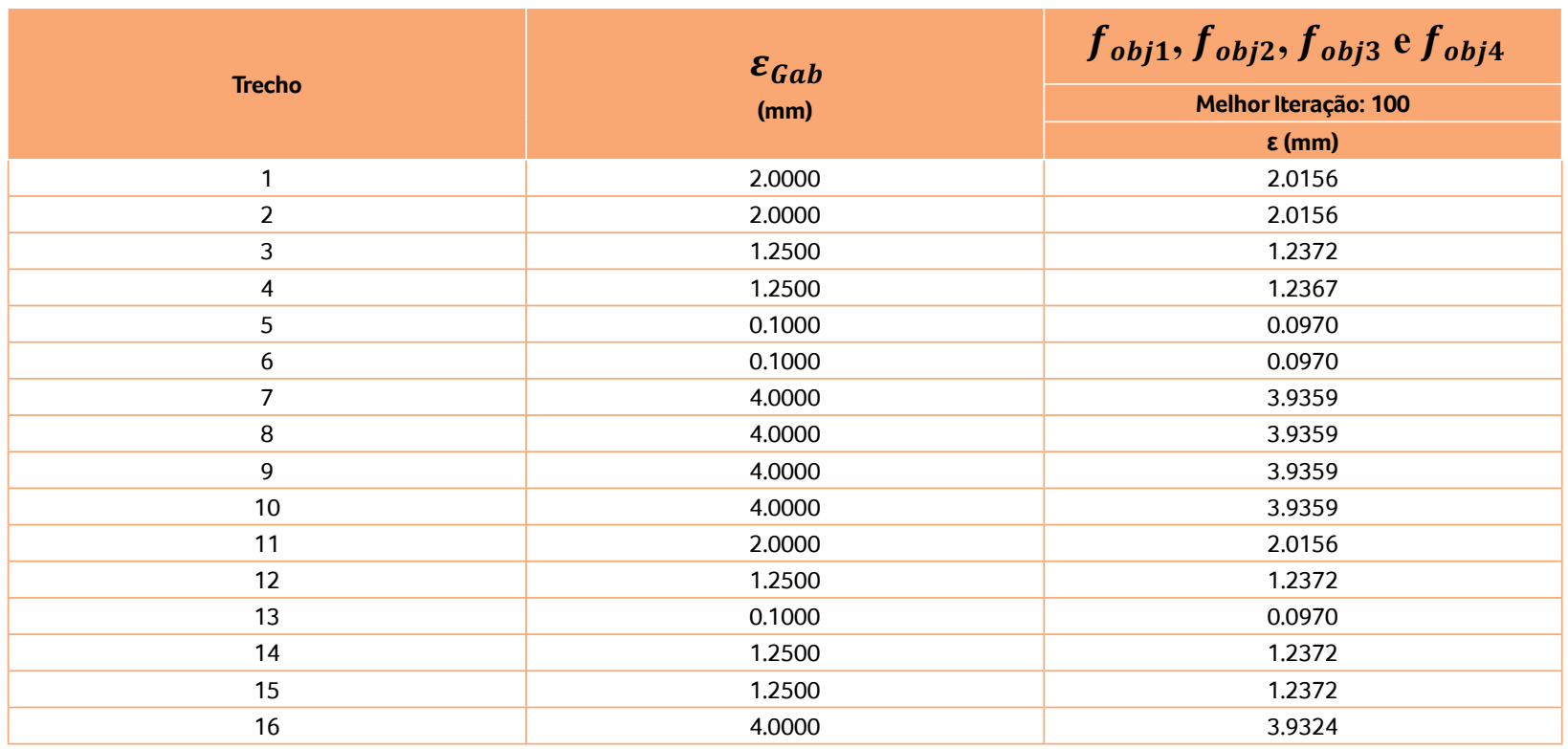

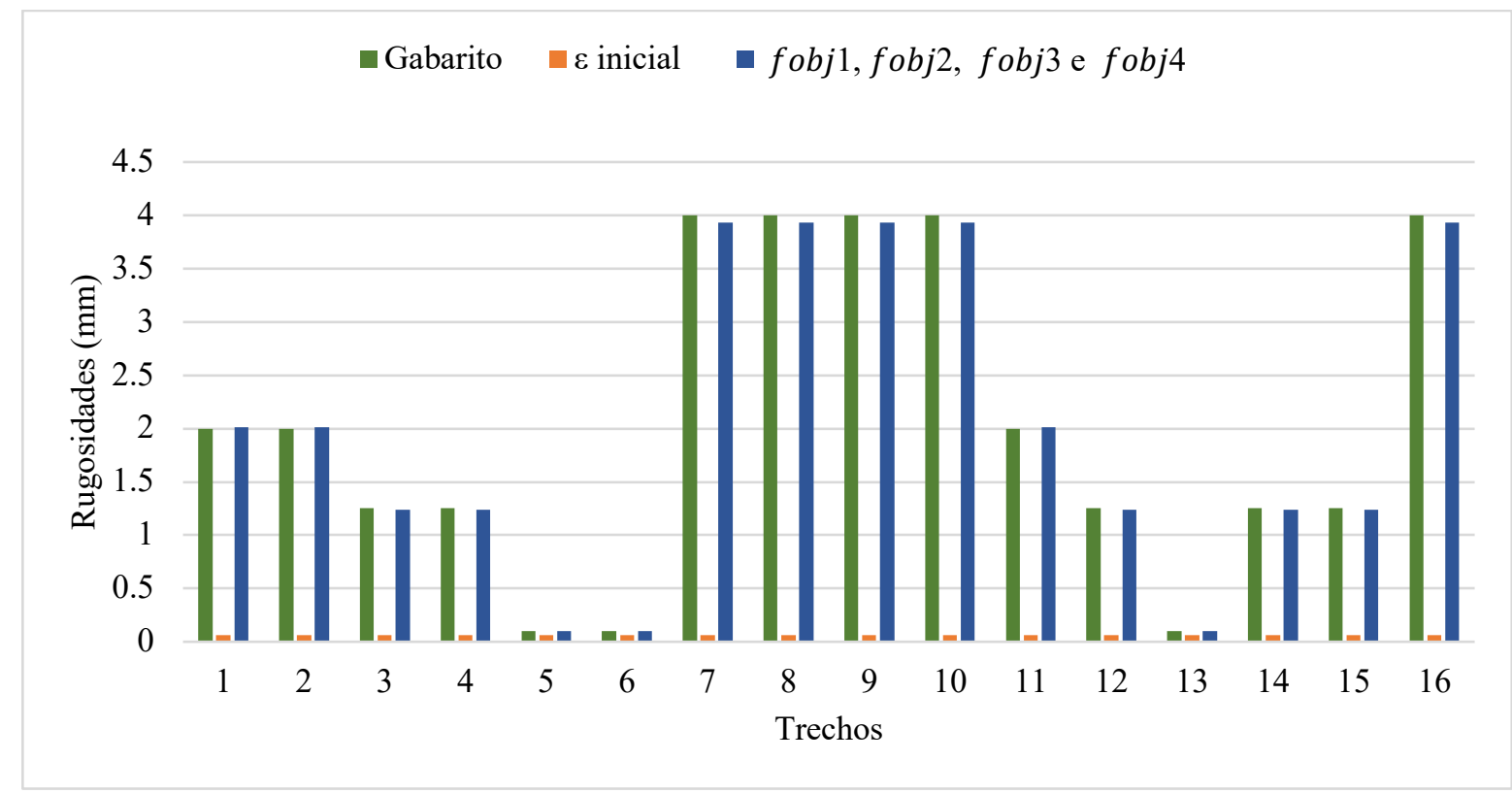

Figura 13 - Gráfico das rugosidades calibradas com 25\% das pressões conhecidas, com a rotina de uniformização. 
Analisando a Tabela 8 e a Fig. 13, observou-se que os resultados obtidos nestas calibrações obtiveram uma precisão muito maior do que as que não utilizaram a nova rotina de uniformização proposta neste trabalho. Percebeu-se também que neste caso as diferentes funções objetivo retornaram a mesma solução.

A Fig. 10 aponta os erros relativos médios calculados nestas calibrações para as pressões, vazões e rugosidades.
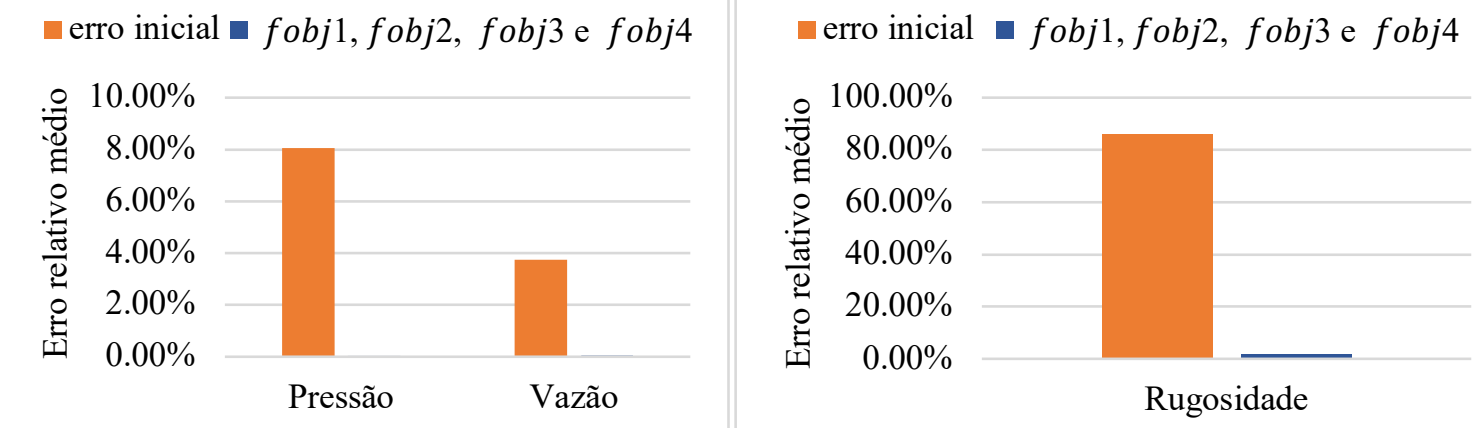

Figura 14 - Erro relativo médio das pressões, vazões e rugosidades para a calibração com $25 \%$ das pressões conhecidas, com a rotina de uniformização.

A Fig. 14 demonstra que as calibrações com o uso da nova rotina melhoraram consideravelmente os valores de pressão, vazão e rugosidade. $O$ erro relativo médio encontrado para as rugosidades foi de apenas $1.54 \%$ para todas essas calibrações. Para as pressões, o valor do erro foi de $0.03 \%$ e para as vazões de $0.05 \%$.

\section{CONCLUSÃO}

A análise das calibrações que utilizaram como dados observados as pressões conhecidas de todos os nós permitiu visualizar que a nova rotina de uniformização obteve melhores resultados, independentemente da função objetivo escoIhida. Apesar disso, as calibrações que não utilizaram a rotina também obtiveram resultados satisfatórios.

Nas calibrações realizadas com $50 \%$ dos nós com pressões conhecidas e sem a utilização da rotina de uniformização, observou-se uma queda na qualidade dos resultados obtidos para as rugosidades e vazões. No entanto, os resultados encontrados pelas calibrações que utilizaram a nova rotina proposta permaneceram excelentes, sinalizando que a nova rotina melhora o método.

$\mathrm{Na}$ análise das calibrações com apenas $25 \%$ dos nós com pressões conhecidas notou-se mais uma vez uma queda na qualidade dos resultados obtidos para as vazões e rugosidades nos testes que não utilizaram a nova rotina. No entanto, os resultados obtidos para as calibrações com o uso da rotina de uniformização seguiram apresentando resultados satisfatórios.

As soluções encontradas neste trabalho sugerem que a nova rotina de uniformização melhora os resultados das calibrações, quando comparados aos resultados sem a rotina. Constatou-se que o novo método diminui o número de dados observados necessários para se adquirir bons resultados. Além disso, notou-se que em todas as calibrações realizadas neste trabalho os erros relativos encontrados para as pressões foram baixos, o que aponta que o método é bastante eficiente para este tipo de dado. Quanto às fun- 
ções objetivo, não se notou nenhum impacto significativo na escolha de qualquer uma delas.

\section{CONTRIBUIÇÃO DOS AUTORES}

Concepção do modelo: Sousa DL, Bezerra AA, Cas-

tro MAH; Desenvolvimento do software: Sousa DL; Realização dos cálculos: Sousa DL; Análise e discussão dos resultados: Sousa DL Castro MAH; Redação: Sousa DL, Bezerra AA, Revisão: Bezerra AA.

\section{REFERÊNCIAS}

BEZERRA, A. A.; CASTRO, M. A. H.; ARAUJO, R. S. A. Absolute roughness calculation by the friction factor calibration using the Alternative Hydraulic Gradient Iterative Method on water distribution networks. Revista Brasileira de Recursos Hídricos, v.22, e24, 2017. http://dx.doi.org/10.1590/ 2318-0331.021720160018

CHENG, W.; HE, Z. Calibration of nodal demand in water distribution systems. Journal of Water Resources Planning and Management, v. 137, n. 1, p. 31-40, 2011. http://dx.doi.org/10.1061/ (ASCE)WR.1943-5452.0000093

GUO, X.; ZHANG, C. M. Use of the physical feature of groundwater flow system to reduce the mathematical complexity in parameter identification: a practical and efficient automated procedure. In: Groundwater Modeling Conference, 1994, Colorado. Proceedings... 1994. p. 111-118. Anais...

IGLEWICZ, B.; HOAGLIN, D. (1993) The ASQC Basic References in Quality Control: Statistical Techniques. In: Mykytka, E.F., Eds., How to Detect and Handle Outliers, ASQC Quality Press, Milwaukee, Vol. 16.

LANSEY, K.E., EL-SHORBAGY, W., AHMED, I., ARAUJO, J., and HAAN, C.T., 2001. Calibration assessment and data collection for water distribution networks. Journal of Hydraulic Engineering, 127 (4), 270-279.
PEREIRA, R. F.; CASTRO, M. A. H. Calibração do coeficiente de decaimento do cloro $(\mathrm{kw})$ em redes de abastecimento de água utilizando o método iterativo do gradiente hidráulico alternativo adaptado para gradiente de concentração. Revista Brasileira de Recursos Hídricos, v. 18, n. 4, p. 67-76, 2013. http://dx.doi. org/10.21168/rbrh.v18n4.p67-76

ROCHA, V. A. G. M.; CASTRO, M. A. H.; ARAÚJO, J. K. Calibração de rugosidade em redes de abastecimento a partir de gradientes hidráulicos através de método iterativo. In: SIMPÓSIO BRASILEIRO DE RECURSOS HÍDRICOS, 18., 2009, Campo Grande. Anais... Campo Grande: ABRH, 2009.

ROCHA, V. A. G. M. Avaliação de calibração de redes hidráulicas usando o Método Iterativo do Gradiente Hidráulico Alternativo (MIGHA) aplicado a escoamento transiente. 2013. 134 f. Tese (Doutorado em Engenharia Civil: área de concentração em Recursos Hídricos) - Universidade Federal do Ceará, Fortaleza, 2013.

SANTOS, A. C. N.; SILVA, F. G. B. Estudo de Calibração de Rugosidades em Rede de Distribuição de Água do Bairro Jardim América MG. Revista Brasileira de Recursos Hídricos, v.18, n.3, p. 261-269, 2013. http://dx.doi.org/10.21168/rbrh.v18n3.p261-269

SCHUSTER, H. D. M.; ARAÚJO, H. D. B. Uma formulação alternativa do método iterativo de gradiente hidráulico no procedimento de calibração dos parâmetros hidrodinâmicos do sistema aqüífero. Revista Brasileira de Recursos Hídricos, v. 9, n. 2, p. 31-37, 2004. http://dx.doi.org/10.21168/rbrh.v9n2.p31-37

TABESH, M. , JAMASB, M. and MOEINI, R. Calibration of water distribution hydraulic models: A comparison between pressure dependent and demand driven analyses, Urban Water Journal, 8: 2, 93 102, 2011. http://dx.doi.org/10.1080/1573062X.2010.548525

VASCONCELOS, G. C. M. P.; COSTA, B. C. A.; ARAÚJO, J. K. Identificação do fator de atrito em rede de distribuição de água por meio do Método do Transiente Inverso - Algoritmo Genético (MTI-AG) e Fórmula de Swamee. Revista Brasileira de Recursos Hídricos, v. 20 , n. 4, p. 980-990, 2015. http://dx.doi.org/10.21168/rbrh. v20n4.p980-990

VASSILJEV, A.; KOOR, M.; KOPPEL, T. Real-time demands and calibration of water distribution systems. Advances in Engineering Software, v. 89, p. 108-113, 2015. http://dx.doi.org/10.1016/j. advengsoft.2015.06.012 